\title{
The impact of computerized provider order entry on emergency department flow
}

\author{
Andrew Gray, MD*; Christopher M.B. Fernandes, MD*; Kristine Van Aarsen, MSc*; \\ Melanie Columbus, MSc, PhD*
}

\section{ABSTRACT}

Objectives: Computerized provider order entry (CPOE) has been established as a method to improve patient safety by avoiding medication errors; however, its effect on emergency department (ED) flow remains undefined. We examined the impact of CPOE implementation on three measures of ED throughput: wait time (WT), length of stay (LOS), and the proportion of patients that left without being seen (LWBS).

Methods: We conducted a retrospective cohort study of all ED patients of 18 years and older presenting to London Health Sciences Centre during July and August 2013 and 2014, before and after implementation of a CPOE system. The three primary variables were compared between time periods. Subgroup analyses were also conducted within each Canadian Triage and Acuity Scale (CTAS) level (1-5) individually, as well as for admitted patients only.

Results: A significant increase in WT of 5 minutes ( $p=0.036$ ) and LOS of 10 minutes $(p=0.001)$, and an increase in LWBS from $7.2 \%$ to $8.1 \%(p=0.002)$ was seen after CPOE implementation. Admitted patients' LOS increased by 63 minutes $(p<0.001)$, the WT of CTAS 3 and 5 patients increased by 6 minutes $(p=0.001)$ and 39 minutes $(p=0.005)$, and LWBS proportion increased significantly for CTAS $3-5$ patients, from $24.3 \%$ to $42.0 \%(p<0.001)$ for CTAS 5 patients specifically.

Conclusions: CPOE implementation detrimentally impacted all patient flow throughput measures that we examined. The most striking clinically relevant result was the increase in LOS of 63 minutes for admitted patients. This raises the question as to whether the potential detrimental effects to patient safety of CPOE implementation outweigh its benefits.

\section{RÉSUMÉ}

Objectif: Un système informatisé d'entrée des prescriptions (SIEP) par des professionnels autorisés a été mis sur pied afin d'améliorer la sécurité des patients en évitant les erreurs de médicaments; toutefois, on ne connaît pas l'incidence du système sur le roulement des patients au service des urgences (SU). Aussi les auteurs ont-ils examiné l'incidence de la mise sur pied du SIEP sur trois indicateurs de performance des SU, soit le délai d'attente (DA), la durée de séjour (DS) et la proportion de patients qui sont partis sans avoir vu de médecin.

Méthode: Une étude rétrospective de cohorte a été menée parmi tous les patients de 18 ans et plus qui ont consulté au SU du London Health Sciences Centre, en juillet et en août de 2013 et de 2014, soit avant et après la mise sur pied du SIEP. Ont fait l'objet de comparaison les trois principales variables relevées durant les deux périodes indiquées. Des analyses de sous-groupes ont aussi été faites pour chacun des niveaux (1 à 5) de l'Échelle canadienne de triage et de gravité (ECTG), séparément ainsi que pour le seul groupe de malades hospitalisés.

Résultats: Une augmentation importante du DA de 5 minutes $(p=0,036)$ et de la DS de 10 minutes $(p=0,001)$ ainsi qu'une augmentation de la proportion de patients partis sans avoir vu de médecin, qui est passée $7,2 \%$ à $8,1 \%(p=0,002)$, ont été observées après la mise sur pied du SIEP. La DS des malades hospitalisés a augmenté de 63 minutes $(p<0,001)$, le DA des patients appartenant aux niveaux 3 ou 5 selon I'ECTG a augmenté de 6 minutes $(p=0,001)$ et de 39 minutes $(p=0,005)$, et la proportion de patients qui sont partis sans avoir vu de médecin a augmenté considérablement chez les patients appartenant aux niveaux 3 à 5 selon I'ECTG, et notamment chez ceux du niveau 5 , qui est passée de $24,3 \%$ à $42,0 \%(p<0,001)$.

Conclusions: La mise sur pied du SIEP s'est répercutée défavorablement sur toutes les mesures de roulement des patients qui ont été examinées. Le résultat le plus manifeste sur le plan clinique est l'augmentation de la DS de 63 minutes chez les malades hospitalisés. Alors, il y a lieu de se poser la question de savoir si les effets potentiellement néfastes de la mise sur pied du SIEP à l'égard de la sécurité des patients dépassent les avantages.

Keywords: electronic, computerized, orders, wait times, length of stay, emergency department

From the *Department of Emergency Medicine, London Health Sciences Centre, London, ON.

Correspondence to: Dr. Andrew Gray, 1810 Blackwater Road, London, ON N5X 4J4; Email: agray6@gmail.com 


\section{INTRODUCTION}

Computerized provider order entry (CPOE) in health care has been introduced across North America based on a business model suggesting savings from improved patient safety. ${ }^{1}$ This improvement is primarily achieved through forcing functions that alert health care providers to potential medication cross-reactions or allergy risks, and to evidence-based clinical decision rules that may favour particular medications or approaches. Carrying out non-advocated approaches frequently requires manual override by the provider. Pain management and encouragement to adhere to complaint-based protocols for specific conditions, such as renal colic and cerebrovascular accidents, are some examples of potential benefits of CPOE. ${ }^{2-4}$ Most problems with CPOE occur with implementation rather than CPOE itself. $^{1}$

Although certain benefits have been found with CPOE, there has been little research on the impact of CPOE implementation on patient flow. Some research suggests CPOE results in prolonged length of stay (LOS) for admitted patients, reduced physician productivity, and increased time to order entry. ${ }^{5-7}$ Other research suggests CPOE reduces LOS, ${ }^{8-9}$ though the evidence for this is either limited to a specific chief complaint or to Emergency Department Information Systems that impact emergency department (ED) patients only. As ED crowding becomes increasingly problematic, the impact of $\mathrm{CPOE}$ on $\mathrm{ED}$ flow must be examined to better evaluate whether it is beneficial (e.g., reduced time to order processing) or detrimental (e.g., slower patient disposition decisions).

The purpose of this study was to evaluate the impact of the implementation of a new hospital-wide Canadian CPOE system on three primary ED variables: LOS, wait time (WT), and the proportion of patients who left without being seen (LWBS) by a physician.

\section{METHODS}

\section{Setting}

London Health Sciences Centre (LHSC), a quaternary care centre in London, Ontario, sees approximately 60,000 ED patients per year through its Victoria campus, and approximately 40,000 ED patients per year through its university campus. It is staffed by certified emergency physicians, with support from two emergency medicine residency programs, and rotating residents from various specialties.

CPOE was introduced in April 2014 under the acronym HUGO (Healthcare Undergoing Optimization). This system impacted all services and disciplines across the organization simultaneously, with education on the new system occurring in the few weeks prior to implementation. HUGO is based on a specific software solution from Cerner Corporation that has been modified for the needs of our institution.

\section{Design}

We conducted a retrospective cohort study of all patients of 18 years and older presenting to LHSC EDs in July and August of 2013 and 2014, before and after the implementation of HUGO. We compared key throughput variables (WT, LOS, and LWBS) between groups before and after implementation. Data were extracted from the LHSC electronic database supported by the health records department. The study was approved through the Research Ethics Board of Western University.

\section{Inclusion and exclusion criteria}

We included all ED patients ages 18 years and older triaged at the study location during July and August of 2013 and 2014. We excluded patients with incomplete or incorrect ED charts. We excluded patients with negative WTs or negative lengths of stay (indicative of an erroneous triage or assessment time recorded) or extreme outliers where WTs exceeded 24 hours (presumed to represent an erroneously wrong day recorded). Any patients missing vital statistics (such as gender or CTAS) were also excluded.

\section{Definition of variables}

The following variables were calculated:

WT (minutes) $=$ time of first physician assessment to time triaged

LOS (minutes) $=$ time of disposition to time triaged LWBS $(\%)=$ number of patients who LWBS/total visits for a given period 


\section{Subgroup analysis}

Subgroup analysis was performed on patients categorized into six a priori subgroups, which consisted of each individual CTAS level (1-5) and an additional analysis performed on admitted patients only. Each subgroup was compared before and after intervention for all three calculated throughput variables defined previously.

\section{Data analysis}

Descriptive statistics were calculated for age, sex, CTAS level, disposition, and total number of patients for each time-period. Variables were examined to determine whether they had a normal or non-normal distribution using the Kolmogorov-Smirnov test. Next, we compared WT and LOS between groups using the Mann-Whitney $U$ test to assess for any overall significant change in these variables for ED patients between each time-period. We compared the LWBS proportion between groups using the chi-square test to assess for any change at each time-period.

Data were entered directly into a passwordprotected, study-specific Microsoft Excel database (Microsoft Corporation, Redmond, WA). All data analyses were performed using SPSS (V. 22.0, IBM Corporation).

\section{RESULTS}

Table 1 provides descriptive statistics of the study population before and after CPOE implementation and illustrates statistics were similar. Table 2 provides all ED throughput variables, suggesting worsening of ED flow after the intervention, though some subgroups were impacted more than others.

\section{DISCUSSION}

We found that implementation of CPOE detrimentally affected three standard ED throughput indicators. Key findings to note were that, after CPOE, LOS for admitted patients was significantly increased, WT for CTAS 3 patients was increased, and the proportion of patients who LWBS was increased. All of these are indicators of worsening crowding and poor ED throughput.

The manner in which ED crowding contributes to the risk of spread for potentially lethal disease has been noted previously. ${ }^{10}$ In the years since, efforts to

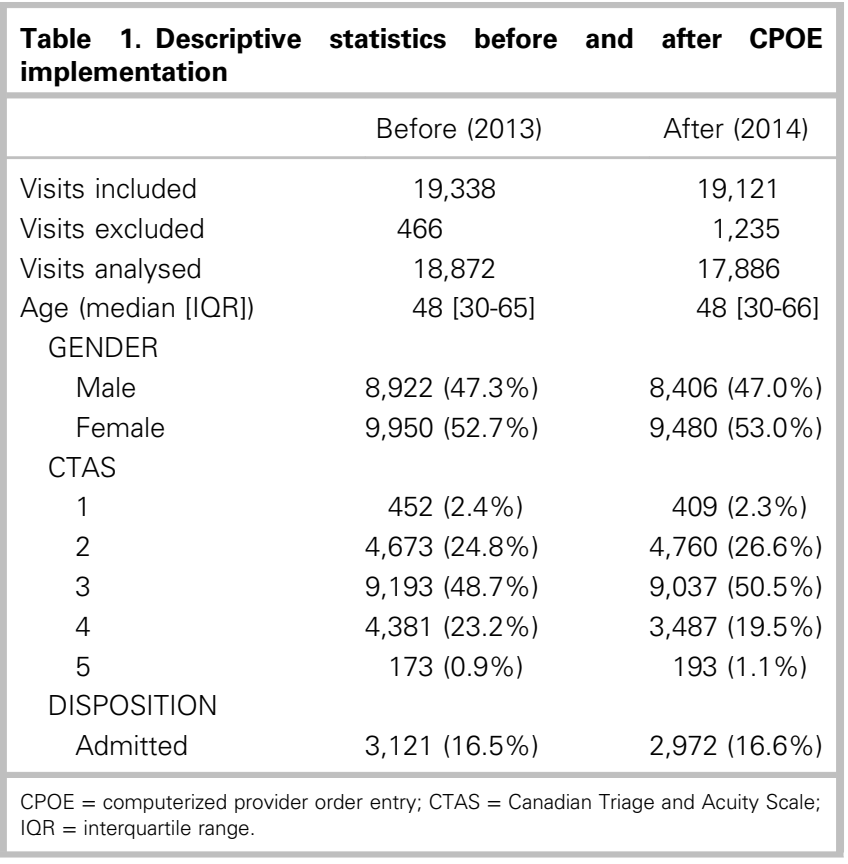

better control hospital flow have yielded mixed results. A number of centres have reported dramatic improvements in ED patient flow, ${ }^{9,11}$ but this has been predicated on improved inpatient access. As Litvak ${ }^{12}$ has shown, efforts such as Lean Thinking ${ }^{13}$ or Toyota Production System ${ }^{14}$ require approximately $80 \%$ inpatient bed occupancy to be successful. Many Canadian hospitals, including ours, function with far higher occupancy, sometimes up to $125 \%$, thus any gains from implementation of these processes may be negligible in such settings. As well, increased boarding time in the ED has been found to correlate with increased mortality. ${ }^{15}$ Thus, dramatically worsening bed occupancy within the ED as may be the case from HUGO implementation, without addressing inpatient occupancy, could contribute to further stretching of limited resources, such as nursing and physician time, and have the potential to worsen patient outcomes.

Our results suggest that HUGO increases ED LOS for admitted patients by a median of 63 minutes. This shows the dramatic effect of poor implementation on the process of patient care. It is difficult to argue that gains through efficiencies would override this inefficiency, particularly when WTs for non-admitted patients have also increased. One concern is that resilient emergency physicians could attempt to overcome this lack of capacity by examining patients in nonstandard locations, such as hallways and chairs. This could lead to more risk to the patient because the 


\begin{tabular}{|c|c|c|c|}
\hline & Before (2013) & After (2014) & $p$ value \\
\hline \multicolumn{4}{|l|}{ ALL VISITS } \\
\hline Median WT (minutes [IQR]) & 78 [33-165] & 83 [33-166] & $=0.036^{*}$ \\
\hline Median LOS (minutes [IQR]) & $254[147-417]$ & 264 [153-442] & $=0.001^{*}$ \\
\hline LWBS & $1,364(7.2 \%)$ & $1,448(8.1 \%)$ & $=0.002^{*}$ \\
\hline \multicolumn{4}{|l|}{ CTAS 1} \\
\hline Median WT (minutes [IQR]) & 5 [0-15] & $4[0-15]$ & $=0.441$ \\
\hline Median LOS (minutes [IQR]) & 301 [130.25-615.75] & 304 [141-621.5] & $=0.759$ \\
\hline LWBS & 0 & 0 & \\
\hline \multicolumn{4}{|l|}{ CTAS 2} \\
\hline Median WT (minutes [IQR]) & 37 [18-67] & 38 [18-72] & $=0.471$ \\
\hline Median LOS (minutes [IQR]) & 301 [179-547] & 307 [186-591] & $=0.041^{*}$ \\
\hline LWBS & $41(0.9 \%)$ & $55(1.2 \%)$ & $=0.178$ \\
\hline \multicolumn{4}{|l|}{ CTAS 3} \\
\hline Median WT (minutes [IQR]) & 113 [51-201] & 119 [57-205] & $=0.001^{*}$ \\
\hline Median LOS (minutes [IQR]) & 275 [170-426] & 279 [169-445] & $=0.635$ \\
\hline LWBS & $706(7.7 \%)$ & $776(8.6 \%)$ & $=0.025^{*}$ \\
\hline \multicolumn{4}{|l|}{ CTAS 4} \\
\hline Median WT (minutes [IQR]) & 114 [52-201] & 117 [56-214] & $=0.068$ \\
\hline Median LOS (minutes [IQR]) & 168 [93-278] & 167 [94-280] & $=0.638$ \\
\hline LWBS & $575(13.1 \%)$ & $536(15.4 \%)$ & $=0.004^{*}$ \\
\hline \multicolumn{4}{|l|}{ CTAS 5} \\
\hline Median WT (minutes [IQR]) & 92 [34-164] & $131[52-241]$ & $=0.005^{*}$ \\
\hline Median LOS (minutes [IQR]) & 131 [56-207] & 163 [96.75-294] & $=0.106$ \\
\hline LWBS & $42(24.3 \%)$ & $81(42.0 \%)$ & $<0.001^{*}$ \\
\hline \multicolumn{4}{|l|}{ ADMITTED } \\
\hline Median WT (minutes [IQR]) & 45 [17-104.5] & 43 [16-103] & $=0.678$ \\
\hline Median LOS (minutes [IQR]) & 713 [443.5-1204.5] & 776 [486-1260] & $<0.001^{*}$ \\
\hline
\end{tabular}

physical exam likely becomes less reliable in a disadvantaged area.

Application of queuing theory demonstrates the negative effect of HUGO on non-admitted patients. We analysed CTAS 3 patients at Victoria campus, which has approximately $40 \mathrm{ED}$ beds, using the M/M/s model for multiple servers with a single queue, ${ }^{12}$ where $s$ is the number of servers (beds available), $\lambda$ is the average number of arrivals per unit of time (approximately four CTAS 3 patients per hour), and $\mu$ is the average number of requests served per unit of time (1/WT, in our case). Most of the time, $s$ is 15 at our Victoria campus (the rest of the beds are taken up by admitted patients or CTAS 1 or 2 cases). In this case, using a queuing theory calculator (e.g., supositorio. com), $W_{\mathrm{q}}$ goes from 0.18 minutes pre-HUGO to 0.31 minutes post-HUGO, where $W_{\mathrm{q}}$ is the average waiting time for a CTAS 3 patient to access the next available bed (a $70 \%$ increase in inefficiency). When we have only 10 available beds, as may be the case when many admitted patients are occupying beds due to increased LOS, HUGO effects escalate for $W_{\mathrm{q}}$ (14.33 minutes to 22.72 minutes). It is arguable that the primary reason that the system is able to function is emergency physician resiliency efforts, as mentioned previously.

It has previously been demonstrated that it is possible to improve LWBS proportion through use of a Fasttrack process. ${ }^{16-20}$ Such a process focuses on CTAS 4 and 5 patients, who otherwise are a very low priority and sometimes even overlooked. The LWBS proportion is primarily a measure of efficiency in the care of CTAS 4 and 5 patients. The Fast-track process is in keeping with modern flow theories that look at streaming of patients to appropriate resources (fewer resources for CTAS 4/5, more for higher acuity 
patients). In our case, we see that the impact of HUGO implementation on LWBS has been most dramatic for the lower acuity patients. Again, any gains from such processes as a Toyota Production System or Lean Thinking will be lessened through poor CPOE implementation. Another possible concern is that patient satisfaction may have worsened as a result of HUGO. It has been shown that the LWBS proportion is an indicator of patient satisfaction ${ }^{16-19}$; an increasing proportion of LWBS may be an early signal that a department may need to urgently address patient dissatisfaction before institutional reputation is permanently harmed.

There are a number of limitations to keep in mind when interpreting our results. Our study was not randomized and was conducted at a single academic health centre, using a unique software package. We did not examine various flow issues through specific days and times, and assessed patients during only 2 specific months in 2 consecutive years. This study did not examine solutions that may have been in the process of implementation by LHSC to solve resultant flow issues. Further, we did not look at the impact of HUGO on specific services and disciplines other than emergency medicine.

An important aspect for future research will be examining whether the throughput variables we assess improved over time. It is possible that we are now further down the "learning curve," and difficulties with efficiency after HUGO have been resolved. Maybe the real lesson here is that CPOE implementation needs to be more thoroughly tested for inefficiencies, and training needs to be more extensive prior to implementation.

\section{CONCLUSIONS}

We found that CPOE implementation at our health care organization detrimentally impacted patient flow in the ED. All throughput variables were involved, some with greater significance than others. The most striking clinically relevant result we found was an increase in LOS of 63 minutes for admitted patients. Our results suggest that the potential patient safety risks may outweigh the benefits when considering CPOE implementation.

Competing interests: None declared.

\section{REFERENCES}

1. Pham JC, Aswani MS, Rosen M, et al. Reducing medical errors and adverse events. Annu Rev Med 2012;63:447-63.

2. Netherton SJ, Lonergan K, Wang D, et al. Computerized physician order entry and decision support improves emergency department analgesic ordering for renal colic. Am 7 Emerg Med 2014;32(9):958-61, doi:10.1016/j. ajem.2014.05.002.

3. Yang JM, Park YS, Chung SP, et al. Implementation of a clinical pathway based on a computerized physician order entry system for ischemic stroke attenuates off-hour and weekend effects in the ED. Am 7 Emerg Med 2014;32(8): 884-9, doi:10.1016/j.ajem.2014.04.049.

4. Blankenship JF, Rogers L, White J, et al. Prospective evaluation of the treatment of pain in the ED using computerized physician order entry. Am 7 Emerg Med 2012; 30(8):1613-6, doi:10.1016/j.ajem.2011.11.003.

5. Bastani A, Walch R, Todd B, et al. Computerized prescriber order entry decreases patient satisfaction and emergency physician productivity. Ann Emerg Med 2010;56(3 Suppl):S83-4.

6. Spalding SC, Mayer PH, Ginde AA, et al. Impact of computerized physician order entry on ED patient length of stay. Am f Emerg Med 2011;29(2):207-11, doi:10.1016/j. ajem.2009.10.007.

7. Syed S, Wang D, Goulard D, et al. Computer order entry systems in the emergency department significantly reduce the time to medication delivery for high acuity patients. Int 7 Emerg Med 2013;6:20, doi:10.1186/1865-1380-6-20.

8. Innes G, Grafstein E, Christenson J, et al. Does computerized physician order entry reduce emergency department length of stay? CFEM 2002;4(2):124-54.

9. Fernandes CMB. Overcrowding in the emergency department: what is our response to the "new normal"? Acad Emerg Med 2003;10(10):1096-7.

10. Crane J, Noon C. The definitive guide to emergency department operational improvement: employing lean principles with current ED best practices to create the "no wait" department. Boca Raton: CRC Press; 2011.

11. Watson RQ, Leeson K. On-the-clock. Quality Progress March 2011: 45-50.

12. Litvak E, Lachman P, Leitch J. Solving flow to enhance safety and decrease costs. Presented at the National Quality Forum, Institute for Healthcare Improvement (IHI); 2014. Available at: http://app.ihi.org/FacultyDocuments/ Events/Event-2491/Presentation-10401/Document8853/Han douts_L23_Handouts_Learning_Lab_IHI_Forum_2014.pdf (accessed February 3, 2015).

13. George ML. Lean six sigma for service. New York: McGraw-Hill; 2003.

14. Liker J, Gardner G.. The Toyota way. New York: McGraw-Hill; 2004.

15. Singer AJ, Thode HC Jr, Viccellio $\mathrm{P}$, et al. The association between length of emergency department boarding and mortality. Acad Emerg Med 2011;18(12):1324-9.

16. Fernandes CMB, Daya MR, Barry S, et al. Emergency department patients who leave without seeing a physician: the Toronto hospital experience. Ann Emerg Med 1994; 24(6):1092-6. 
17. Fernandes CMB, Christenson JM. Use of continuous quality improvement to facilitate patient flow through the triage and fast-track areas of an emergency department. 7 Emerg Med 1995;13(6):847-55.

18. Fernandes CMB, Christenson JM, Price A. Continuous quality improvement reduces length of stay for fast-track patients in an emergency department. Acad Emerg Med 1996;3(3):258-63.
19. Fernandes CMB, Price A, Christenson JM. Does reduced length of stay decrease the number of emergency department patients who leave without seeing a physician? 7 Emerg Med 1997;15(3):397-9.

20. Al Darrab A, Fan J, Fernandes CMB, et al. How does fast track affect quality of care in the emergency department? Eur 7 Emerg Med 2006;13(1):32-5. 